\title{
Assessment of Principled Moral reasoning of a Female Sample of Graduate students in Education
}

\author{
Djilali Bouhmama
}

Kuwait University

\begin{abstract}
The purpose of this study was to measure the principled moral reasoning of 68 female graduate students in education at the University of Kuwait. Participants were recruited from three master programs: foundations of education $(n=21)$, curriculum and method of teaching (29), and Administration and educational planning (18). Their moral reasoning was measured by the Defining Issues Test (DIT). The results indicate that the sample scored lower in principled moral reasoning than graduate students in general. However, they scored predominantly at stage 4 in Kohlberg's moral judgment theory. Results also indicate that there are no significant differences in principled moral reasoning of the participants according to their academic disciplines.
\end{abstract}

Keywords: Principled moral reasoning, academic disciplines; graduate student; Defining Issues test; moral judgment; Kohlberg theory. 


\section{NREL}

$2^{\text {nd }}$ International conference on Advanced

\section{Introduction and theoretical background}

Research on moral reasoning has received much attention for many years since the inception of Kohlberg's theory about morality and moral development (Cummings, Dyas, Maddux, \& Kochman, 2001; Gump, Baker , \& Samuel 2000) ; Rest, Thoma \& Edwards 1997 ; Wygant \& Williams, 1995). Kohlberg (1969; 1984) developed a comprehensive theory of stages of moral development. He argues that people progress in moral reasoning through a hierarchy of stages. Kohlberg's stages are grouped into three progressively higher levels: preconventional, conventional, and postconventional. People at the preconventional level (Stages 1 and 2), primarily children, conceive of rules and social expectations as external to the self. Moral decisions are made based on expectations of reward or punishment. At the conventional level (Stages 3 and 4), people subscribe to a morality of shared norms and values, centering on the needs of the individual and the rules and expectations of others. Interpersonal relationships and concern for others' opinions are crucial (Stage 3). At Stage 4, obeying society's laws becomes central. At the postconventional level (Stages 5 and 6), moral decision-making is based on principled reasoning. Stage 5 revolves around the utilitarian maxim, "the greatest good for the greatest number." At Stage 6, people make decisions based on universal principles of justice, liberty, and equality, even if these violate laws or social norms (Kohlberg, 1969; Power, Higgins, A \& Kohlberg, 1989).

The theory of moral development proposed by Kohlberg (1969) has been widely used in research examining the reasons individuals use in making moral judgments (Snarey 1985; Trevino 1992). The most influential research focusing on moral development in student populations was research done by Lawrence Kohlberg (1958, 1964, 1967, 1969). Since Kohlberg's inception of his theory, considerable studies of moral judgment among college and university students have been undertaken predominantly with Western students' populations and most often with males. Recent years, however, have witnessed a growing interest and concern among researchers in studying the moral reasoning of graduate students. Thus, a substantial amount of research on the moral reasoning of graduate students has been undertaken in a wide variety of cultural groups, predominantly, however, in the United States (e.g. Cummings, Maddux, Richmond, \& Cladianos, (2004); Fly, van, Weinman, Kitchener, \& Long, (1997); Folse, ( 1991 ); Fox, (2003); Hornsby (2007); Hull., James-Valutis, 
\& Triggle. (1994) ; Isakson , Rawwas, \& Swaidan, (2007) ; Riesch, von Sadovszky, Norton, \& Pridham. (2000); Smith, Strand, \& Bunting. (2002); Thomas, Jones, \& Agle (1991); Welton, LaGrone, \& Davis, (1994); Woodward, Davis, \& Hodis, (2007). However, there is a dearth of empirical research regarding moral development of Muslim graduate students. To the best knowledge of the present authors, based on a comprehensive review of relevant literature, no research on Arab Muslim graduate students has been attempted. Only few studies have been carried out on high schools and undergraduate students from Arab Muslim cultures (Bouhmama, 1984, 1988, 1989, 2007; Ismail, 1976; Maqsud, 1977, 1998; Webb \& Steentsma, 1983).

Of the methods of measuring moral reasoning, the most widely used is the Defining Issues Test (DIT), a technically strong, objective paper-and-pencil test. The Defining Issues Test is a well-documented measure of moral judgment that has been used all over the world (Rest, 1986). The index most frequently used is the "P-score," which reflects the principled reasoning (Stages 5 and 6 in Kohlberg's theory) of a person.

In the present investigation, the authors sought to find answers to the two research questions listed below:

1. What is the principled moral reasoning level of a female sample of Kuwaiti graduate students, as measured by the P-score of Defining Issues Test?

2. Are there significant differences in moral reasoning levels of the participants based on their academic disciplines?

\section{Methodology}

\subsection{Participants}

Participants were 68 female graduate students in education, from three master programmes at the college of Education, Kuwait University: Master of foundations of education $(n=21)$, Master of Curriculum and methods of teaching ( $n=29)$, \& Master of Administration and educational planning $(n=18)$. All participants were Muslims and were either full time or part time teachers with a teaching experience ranging from 3 years to 13 years. They were between the ages 25 and 39, with a mean age of 27, 6 and a standard deviation of 2, 36 . 
The initial sample consisted of 73 subjects; however, 5 protocols $(6.8 \%)$ were discarded because of inconsistencies. The loss of $6.8 \%$ of the respondents in this study due to invalidating from the internal consistency checks is within the expected 5-15\% that DIT studies usually incur (Rest, 1990, 1993).

\subsection{Instrumentation.}

The moral reasoning was assessed by the Arabic version of the Defining Issues Test (Short Form) which has been employed in previous published research (Bouhmama, 1989, 2007). The Defining Issues Test (DIT) was developed by Rest (1997) to function as an objective alternative to the subjective and time-consuming Moral Judgment Interview designed by Kohlberg. Both were designed to measure moral development level of the participant according to Kohlberg's theory of moral development. The short-form of the DIT is composed of three dilemmas.

Stage scores and principled morality scores were obtained for each participant. The principled morality score ( $\mathrm{P}$ score) represents the amount of post-conventional thinking (stages 5A, 5B, and 6) preferred by the participants. This is the score used to distinguish those making a high percentage of principled morality decisions from those thinking mostly at pre-conventional and conventional levels (stages 2, 3, and 4). The P-score (based on moral judgment Stages 5 and 6) is the most valid and widely used index. Since the P score was used as the moral development variable in this study, reliability and validity of the DIT will be discussed in terms of that score alone. A study of test-retest reliability by Davison and Robbins (1978) showed the P score to have a reliability of generally .80. A Cronbach's Alpha measure of internal consistency provided an alpha in the .70s for the P score of both the sixstory version and the short form. The three stories making up the short form used in this study (Heinz and the Drug, Escaped Prisoner, and the Doctor's Dilemma) were chosen for their high $\mathrm{P}$ score correlation $(\mathrm{r}=.93)$ with the P score of the original six-story version (Rest, 1990). 


\subsection{Procedure}

The short Arabic version of the Defining Issues test DIT was administered to the participants in regular class session under the supervision of research assistants for each of the three academic programs. Prior to the distribution of the test materials, a brief statement of the importance of this type of research was provided in order to elicit more co-operation from the participants. The students took part in the study of their own volition. They completed the questionnaire after they had been given a brief explanation of the DIT; they were given approximately 40 minutes to complete the survey in class.

\section{RESULTS}

Of the 73 students who participated in this study, 5 (6.8\%) were excluded from further analysis because of features of their protocols that suggested careless responding, such as missing data, or nondiscriminating rankings. These exclusions were made based on criteria set by Rest (1990)

Research question 1: What is the principled moral reasoning level of the Kuwaiti graduate students, as measured by the P-score of Defining Issues Test?

Table 1 presents the distribution of moral stage scores for 68 female Kuwaiti graduate students in Education. These results answer the first question of the study related to the use of the sample of the Principled Moral reasoning level as measured by the P score of the Defining Issues Test (DIT).

TABLE 1: Distribution of DIT Moral stage scores for the whole sample $(\mathrm{N}=68)$

\begin{tabular}{|l|l|l|}
\hline Stages & Mean & SD \\
\hline 2 & 7.14 & 04.28 \\
\hline 3 & 23.45 & 09.43 \\
\hline 4 & 41.06 & 11.48 \\
\hline $5 \mathrm{~A}$ & 16.31 & 08.50 \\
\hline $5 \mathrm{~B}$ & 08.70 & 07.32 \\
\hline 6 & 07.67 & 04.52 \\
\hline $\mathrm{P}$ & 32.68 & 13.12 \\
\hline
\end{tabular}


The results for the Kuwaiti female students for this study indicate that the percentage of their principled Moral reasoning level is 32.68 as expressed by the $\mathrm{P}$ score. The scores from the DIT yielded an interesting trend for the present sample. The sample mean of the principled moral reasoning score expressed by Rest P-score was considerably below $(\mathrm{P} \%=32.68)$ the group means in the normative data provided by Rest, 1994; Rest \& Narvaez, 1994 (p.4), who reported that Junior high school subjects generally average in the 20 s, the senior high school subjects generally average in the 30 s, the college students average in the 40s, the graduate students (who are not specializing in majors emphasizing moral thinking) average in the 50s, and those graduate students who do specialize in moral thinking average in the $60 \mathrm{~s}$.

It is also evident from the above table 1 above that the participants have a profile of moral development with stage 4 of moral reasoning as predominant (41.06). As can be seen from the table 1, the means of the scores for the graduate female students in Education were higher for the conventional moral reasoning (41.06), than for the post conventional moral reasoning (32.68).

Findings of the present research corroborate the findings of some previous research studies of moral reasoning in education students, which indicate that these students demonstrate significantly lower principled moral reasoning than college students major in other disciplines (Almpe, 1994; Cummings, Dyas, Maddux, and Kochman, 2001; McNeel, 1994; Yeazell \& Johnson, 1988)

Research question 2: The second question of this study sought to determine if there are differences in the participants' scores on principled moral reasoning (P-score) in terms of their academic type of discipline.

According to Rest (1990), when the purpose of a study is to compare two or more groups in terms of moral reasoning, t-tests or ANOVA are appropriate tests of significance on the DIT's P-scores. Accordingly, the average P-scores of the three master groups were tested for statistical significance. Table (2) displays Means and Standards deviations for the DIT Principled Moral reasoning score (P-score) according to discipline of the participants. 


\section{$2^{\text {nd }}$ International conference on Advanced Research in Education, Teaching \& Learning}

Table (2) Means, standard deviations and F- values of moral scores according to Academic disciplines

\begin{tabular}{|c|c|c|c|c|c|c|c|c|}
\hline \multirow[t]{2}{*}{ Stage } & \multicolumn{2}{|c|}{$\begin{array}{l}\text { Master Foundations of } \\
\text { Education } \\
(\mathrm{n}=21)\end{array}$} & \multicolumn{2}{|c|}{$\begin{array}{c}\text { Master Curriculum \& } \\
\text { Methods of teaching }(n=29)\end{array}$} & \multicolumn{2}{|c|}{$\begin{array}{c}\text { Master Admini \& } \\
\text { Educational Planning } \\
\qquad(\mathrm{n}=18)\end{array}$} & \multirow[t]{2}{*}{ F-value } & \multirow[t]{2}{*}{ Significance $(p)$} \\
\hline & Means & SDs & Means & SDs & Means & SDs & & \\
\hline 2 & 06.09 & 05.85 & 08.21 & 06.57 & 07.14 & 05.46 & 0.747 & 0.478 \\
\hline 3 & 22.76 & 19.78 & 23.38 & 20.19 & 24.23 & 18.32 & 0.027 & 0.973 \\
\hline 4 & 42.72 & 18.56 & 40.56 & 21.47 & 39.92 & 24.58 & 0.093 & 0.911 \\
\hline $5 \mathrm{~A}$ & 17.35 & 13.36 & 15.74 & 12.53 & 15.85 & 13.04 & 0.133 & 0.876 \\
\hline $5 B$ & 09.75 & 07.80 & 08.55 & 06.73 & 07.82 & 05.86 & 0.189 & 0.828 \\
\hline 6 & 08.32 & 05.25 & 07.12 & 04.45 & 07.57 & 06.35 & 0.266 & 0.767 \\
\hline $\mathrm{P}$ & 35.42 & 14.76 & 31.41 & 12.66 & 31.24 & 15.32 & 0.611 & 0.546 \\
\hline
\end{tabular}

Results of the analysis of variance shown in Table (2) indicate that there are no significant differences between Principled Moral reasoning according to the academic disciplines of the three master groups who participated in this present study.

Table (2), also provides a summary of the statistical results for the whole profile of moral reasoning scores for the three master education groups according to their academic disciplines.

\section{4-DISCUSSION}

Results of the present study indicate that Kuwait female graduate students use principled moral reasoning less than expected based on their level of education. Although all the respondents are graduate students, the obtained mean of principled moral reasoning (postconventional thinking) of 32.68 was equivalent to Senior high school students (31.80) and less than adults in general (40.0) as reported by Rest and Narvaez (1994), and indicating that in terms of moral judgment, the subjects in this present study scored much lower than other graduate student groups from western societies.

Findings of the present research corroborate the results of some previous research studies of moral reasoning in education students, which indicate that these students demonstrate significantly lower principled moral reasoning than college students major in other 


\section{NREL}

$2^{\text {nd }}$ International conference on Advanced

disciplines (Almpe, 1994; Cummings, Dyas, Maddux, and Kochman, 2001; McNeel, 1994; Yeazell \& Johnson, 1988)

However, respondents used stage 4 moral reasoning ("law and order moral orientation" or

" maintaining norms") more frequently than expected (41.06). These findings support Stewart and Sprinthall (1993) and Mwamwenda (1991)'s findings of decreased P scores and increased stage 4 scores in a sample of graduate students at the Department of Educational Psychology, University of Alberta.

The profile of the moral reasoning of the present sample shows the predominance of the conventional morality and a descent in advanced stages, as it appears in other studies using the same instrument the DIT test and with different students' samples (e.g. Bouhmama, 2007; Mwamwenda, 1991). One tentative explication for the low score of the participants' principled moral reasoning in this present study is that there are more likely factors in their disciplines or in their curricula that may account for their low score .Curriculum related factors that may contribute to the moral reasoning scores of these subjects which may be attributed to failure to integrate instruction of ethical considerations within the curriculum or to differences in teaching methodology (McNeel, 1994). According to Rest, Narvaez, and Thomas (1999) "The critical characteristic of a college for promoting moral judgment seems to be a commitment to critical reflection "(p.73). This characteristic may be lacking in the curriculum of the master education programs of these subjects, and perhaps the master curriculum does not provide enough exposure to specific ethical considerations which resulted in their lower principled moral reasoning. These research findings indicate the need for closer examination of curriculum content and teaching methods to respond to the question of what best equip students with the critical thinking needed for postconventional reasoning (Kaplan, 2006; McNeel, 1994). McNeel (1994) found that the highest growth in moral reasoning in students whose majors were in areas "that focus on understanding humans in all diversity and/or majors that include a central integration of ethical considerations with the content of a professional course of study" (p.34). Indications of specific processes, content and ethics training that would be most helpful, in promoting 
principled moral thinking include interactive components such as discussion groups that accompany lecture presentations, thoughtful reflection, and reading in moral philosophy . (Hull, Wurm-Schaar, James-Valutis, and Triggle, 1994; Rest, 1994)

The second question of this study sought to determine if there are differences in the participants' scores on principled moral reasoning (P-score) in terms of their academic type of discipline. Results indicate that specific academic programs did not influence principled moral reasoning. The lack of a significant difference between the participants ' principled moral reasoning as well as other DIT scores as indicated in Table 2 above, could be explained as due to the opportunity sample used in this study on one hand and the lack of equal number of subjects in each group as categorized according to their academic disciplines, on the other hand. Another possible explanation for the failure of findings significant differences in the moral judgment scores as a result of the academic major, could be the homogeneity of the sample with regard to religious affiliation as all the participants were Muslims . Overall, this finding is quite consistent with several previous research findings (Goodman \& Crawford, 1974; Laczniak \& Inderrieden, 1987; McNichols \& Zimmer, 1985). However, two other studies did find significant moral judgment differences regarding academic majors (Beltramini, Peterson, \& Kozmetsky, 1984). Further instigations are needed to clarify this inconsistency.

\section{Conclusion.}

The main thrust of this study was to explore the principled moral reasoning of a female sample of graduate students in education at the University of Kuwait. The findings suggest that the participants would show less preference to advanced levels of moral reasoning (postconventional reasoning) than their counterparts in other similar investigations reported in moral development literature. This finding seems rather distressing, given their level of education .The low principled moral reasoning level of the participants suggest that more attention needs to be paid to their moral judgment development .This may require ethics and values education to be integrated throughout the curriculum, as the existing programs do not seem to offer such needed specific ethics courses, in addition to the introduction of a teaching methodology based on critical reflection to promote their higher level of moral 
reasoning, as suggested by previous research literature in the domain of moral development (Rest, 1994; McNeel,1994; Kohlberg and Berkowitz, 1981).

\section{References}

Bouhmama, D. (2007) Patterns of moral reasoning and their relationship with sex and educational level of a sample of Kuwait University students. The Educational Beltramini, R. F., Peterson, R. A., and Kozmetsky, G. (1984) Concerns of College Students Regarding Business Ethics. Journal of Business Journal, 21(84), pp. 13-51. (In Arabic)

Bouhmama, D. (1989) The moral judgment of Algerian University students. The Educational Journal, 6(21), pp. 107-134. (In Arabic)

Bouhmama, D. (1988) Relation of formal education to moral judgment development, Journal of Psychology, 122(2), pp. 155-158.

Bouhmama, D. (1984). Assessment of Kohlberg's stages of moral development in two cultures Journal of Moral Education, 13(2), pp. 124-132.

Cummings, R., Maddux, C., Richmond, A. S., \& Cladianos, A. (2004). Principled moral reasoning of graduate students in education and counseling: Assessment and intervention, Higher Education Abstracts, 40(1), 83.

Cummings, R., Dyas, L., Maddux, C. D., \& Kochman, A. (2001). Principled moral reasoning and behavior of preservice teacher education students, American Education Research Journal, 38(1), pp. 143-158.

Davison, M. and Robbins, S. (1978). The Reliability and Validity of Objective Indices of Moral Development Applied Psychological Measurement, 2(3), pp. 391-403.

Felton, G.M, \& Parsons, M, A. (1987). The impact of nursing education on ethical/moral decision making, Journal of Nurse Education, 26(1), pp. 7-11 
Fly, B. J., Van W. P. Bark., Weinman, L., Kitchener, K. S., \& Long, P. R. (1997) Ethical transgressions of psychology graduate students: Critical incidents with implications for training. Professional Psychology, Research and Practice, 28, pp. 492-495.

Folse, K. (1991) Ethics and the profession: Graduate student training. Teaching Sociology, 19, pp. 344-350.

Fox, J.P. (2003) Waking the Walk: Does Moral Judgment Equal Ethical Behavior? M.A thesis, Marywood University, Scranton PA Goodman,C.s., \& Crawfod,C.M. (1974). Young executive: A source of new ethics? Personnel Journal, 53(March), pp. 180-187.

Gump, L.S., Baker, R.C., \& Roll, S. (2000) Cultural and gender differences in moral Judgment: A study of Mexican Americana and Anglo-Americans,_Hispanic Journal of Behavioral Sciences, 22, pp. 78-93.

Hornsby, K. (2007) Developing and Assessing Undergraduate Students' Moral Reasoning Skills, International Journal for the Scholarship of Teaching and Learning, 1(2), pp. 1-18. Hull, R; Wurm-Schaar, M; James-Valutis, M. \& Triggle D. (1994) The Effect of a Research Ethics course of Graduate Students' Moral Reasoning, National Academy of Sciences, Washington, D.C. July 5-6.

Isakson, H ; Rawwas, M; \& Swaidan,Z .(2007) A comparative study of ethical beliefs of master of business administration students in the United States with those in Hong Kong, Journal of Education for Business, 82 (3 ), pp. 146-158

Ismail, M. A. (1976) A cross-cultural study of moral judgment: The relationship between American and Saudi Arabian University students on the Defining Issues Test, Unpublished doctoral dissertation, Oklahoma University.

Kaplan, L.E. (2006) Moral reasoning of MSW social workers and the influence of education, Journal of Social Work Education, 42, (issue 22 sept-06).

Kohlberg, L. (1958) The Development of Modes of Moral Thinking and Choice in the 10 to 16 Years, Unpublished dissertation, University of Chicago. 


\section{NREL}

$2^{\text {nd }}$ International conference on Advanced

Kohlberg, L. (1964) Development of Moral Character and Moral Ideology, in Review of Child Development Research, Vol. 1, Hoffman (Ed.), Russell Sage Foundation, New York.

Kohlberg, L. (1967) Moral and Religious Education and the Public Schools: A Developmental View, in Religion and Public Education, T. Sizer (Ed.), Houghton-Mifflin, and Boston, MA.

Kohlberg, L. (1969) Stage and Sequence: The Cognitive Developmental Approach to Socialization, in Handbook of Socialization Theory and Research, D. Goslin (Ed.), Rand McNally, Chicago, pp. 341-480.

Kohlberg, L. (1984) Essays on Moral Development. New York: Harper \& Row.

Laczniak, G., \& Inderrieden, E.J. (1987) The influence of stated organizational concern upon ethical decision making, Journal of Business Ethics, 6, pp. 297-307.

Maqsud, M. (1977) Moral reasoning of Nigerian and Pakistani Muslim adolescents, Journal of Moral Education, 7(1), pp.40-49.

Maqsud, M. (1998) Moral orientations of Batswana high school pupils in South Africa, Journal of Social Psychology, 130, pp. 255-257

McNeel, S. (1994) College teaching and student moral development. In J. Rest, \& D.

Narvaez (Eds.), Moral development in the professions: Psychology and applied ethics (pp. 27-49). Hillsdale, NJ: Erlbaum.

McNichols, C.W., \& Zimmer, T.W. (1985) Situational ethics: An empirical study of differentiators of students' attitudes, Journal of Business ethics, pp.175-180.

Meisels, S.J., Bickel, D.D., Nicholson, J., Xue, Y. \& Atkins-Burnett, S. (2001) Principled moral reasoning and behavior of preservice teacher education students, American Educational Research Journal, 38 (1) pp. 143-158

Mwamwenda, T. (1991) Graduate students moral reasoning, Psychological Reports, 68(3) pt2, pp 1368-1370. 
Power, F. C., Higgins, A., \& Kohlberg, L. (1989) Lawrence Kohlberg's Approach to Moral Education. New York: Columbia University Press.

Vol, 10, pp. 1-21.

Rest, J. R. (1994). Background: Theory and research. In J. R. Rest \& D. Narvaez (Eds.), Moral development in the professions: Psychology and applied ethics (pp. 1-26). Hillsdale, NJ. Erlbaum.

Rest, J. R. (1993) Guide for the Defining Issues Test, Minneapolis: Center for the Study of Ethical Development.

Rest, J. (1990), DIT Manual. 3rd ed., Minneapolis: Center for the Study of Ethical Development.

Rest, J. (1986) Moral development: Advances in research and theory. New York: Praeger.

Rest, J. R. (1979) Development in judging moral Issues, Minneapolis: University of Minnesota Press.

Rest, J. R., \& Narvaez, D., (eds.) (1994) Moral development in the professions: Psychology and applied ethics, Hillsdale, NJ: Erlbaum. (p14)

Rest, J., Thoma, S., \& Edwards, L. (1997) Designing and validating a measure of moral judgment: Stage preference and stage consistency approaches, Journal of Educational Psychology, 89(1), pp. 5-28.

Riesch, Susan K.; von Sadovszky, Victoria; Norton, Sally; Pridham, Karen F. (2000) Moral Reasoning among Graduate Students in Nursing, Nursing Outlook, 48 (2 ), pp. 73-80.

Snarey, J. R. (1985) Cross-cultural universality of social-moral thinking. A critical review of Kohlbergian research, Psychological Bulletin, 97, pp. 202-231.

Smith, C.A., Strand, S.E. \& Bunting, C.J. (2002). The influence of challenge course participation on moral and ethical reasoning, Journal of Experiential Education, 25 (2), pp. $278-280$. 
Stewart, D. W., and Sprinthall, N. A. (1993). The Impact of Demographic, Professional and Organizational Variables and Domain on the Moral Reasoning of Public Administrators. In H.G. Frederickson, (Ed.). Ethics and Public Administration, Armonk, N.Y.: Sharpe.

Thomas, T., Jones, T., \& Agle, B.R. (1991), Gauging the Impact of Business Education on the Moral Development of Students, International Association for Business and Society 1991 Proceedings, pp. 587-601.

Trevino, L. (1992) Moral Reasoning and Business Ethics: Implications for Research, Education, and Management, Journal of Business Ethics, pp. 445-459

Webb, R., \& Steentsma, I.R. (1983). A study of moral reasoning by Palestinian Arabs, Paper presented at the $91^{\text {st }}$ Annual Convention of the American Psychological Association, Anaheim, CA, and August 26-30, 1983).

Welton, R.E., LaGrone, R.M., Davis, J.R. (1994) Promoting the moral development of accounting graduate students: an instructional design and assessment, Accounting Education, 3 (1), 35-50.

Woodward, B; Davis, D. C. and Hodis , F.A. (2007) The Relationship Between Ethical Decision Making and Ethical Reasoning in Information Technology Students , Journal of Information Systems Education, 18 ( 2), pp.193-202

Wygant, S. A., \& Williams, R. N. (1995) Perceptions of a principled personality: An interpretive examination of the Defining Issues Test, Journal of Social Behavior and Personality, 10(1), pp. 53-66.

Yeazell, M.I., \& Johnson, S.F. (1988) Levels of moral judgment of faculty and students n a teacher education program: A micro study of an institution, Teacher Education Quarterly, 15(1), pp.61-70. 